\title{
The Empirical Study of Lexical Approach in College English Classroom Teaching and its Effects on Art Major's Writing
}

\author{
Jianwei Wang ${ }^{1}$ \\ ${ }^{1}$ College of Foreign Languages, Taishan University, Taian, Shandong, China \\ Correspondence: Jianwei Wang, College of Foreign Languages, Taishan University, Taian, Shandong, China.
}

Received: November 3, 2021

Accepted: November 30, 2021

Online Published: November 30, 2021

doi: $10.5539 /$ elt.v14n12p227

URL: https://doi.org/10.5539/elt.v14n12p227

\begin{abstract}
Lexical approach has been believed to be an ideal way for language teaching and learning, but few empirical studies are concerned with the effects that lexical approach has on art major students' English writing. This study aims to explore the effects the lexical has on writing through an experiment in which the lexical approach was applied in an English class for art majors. All of them attended the pre-test before the experiment and the post-test after the experiment. Through analyzing the data of composition scores and the number of lexical chunks used in compositions by paired sample $t$ tests, this study finds that the lexical approach has positive effect on art majors' writing proficiency and it is quite feasible and effective to apply the lexical approach to college English teaching, especially in English writing teaching.
\end{abstract}

Keywords: art majors, college English teaching, lexical approach, writing

\section{Introduction}

Writing is one of the four basic skills of language. The teachers and students in China have devoted much time and energy to improving their writing proficiency. However, it seems that the results are far from satisfactory. Statistics in CET-4 and 6 (CET is short for College English Test, which is a very popular and reliable test to measure college students' English proficiency in China) show that college students' writing proficiency stagnates and remains at the same level while their overall performance manifests a tendency of improvement (Qi, 2005). This is even worse for art major students whose English proficiency is much lower than non-art majors. They know little about grammar in English and accumulate few words and phrases. In a result, they have much difficulty in achieving fluency, accuracy and idiomaticity in their short compositions. Moreover, when they are required to write a composition, they tend to have some thoughts at first in Chinese in their mind and then try to find corresponding English words for Chinese words one by one, and finally they combine them together word for word on the basis of grammar to construct English sentences. Therefore, it is really needed to find a way to better art major students' writing.

The lexical approach was first proposed by Lewis and his associates in 1993 and it holds the idea that lexical chunks are at the center of language learning and teaching. Lexical chunks are the units of forms and functions. They can be stored and retrieved as a whole, and thus they can lighten the burden of memory and offer the shortcut for language processing in certain contexts. So the lexical approach may be an ideal way to improve art majors' writing proficiency. Many studies (Ellis, 1999; Lewis, 2000; Perera, 2001; Richards \& Rodgers, 2008) have found that lexical chunks play a central role in both L1 and L2 acquisition and they are believed to be the smallest units of memory and production of a language.

In recent years, the linguists and researchers in China have conducted a series of researches about lexical chunks from different perspectives. Some of them are concerned with the survey of Chinese students' use of lexical chunks (Gao, 2017; Ma, 2009; Qi \& Ding, 2011; Xu, 2010); others focus on the relationship between the use of lexical chunks and writing proficiency (Ding \& Qi, 2005; Du, 2016; Zhang, 2008) and still others are associated with the role of lexical chunks in language acquisition (Chen, 2008; Gai, 2010; Han, 2011; Hu, 2015; Yang, 2015). However, few of them are concerned with the effects the lexical approach has on art majors' writing, particularly through applying the lexical approach to college English reading and writing course for art majors. Therefore, the present study aims to answer the following questions through applying the lexical approach to college English reading and writing course for art-major students: 1) What differences do students show in the use of lexical chunks in writing after the application of lexical approach in their English classroom? 2) Is there 
any correlations between the use of lexical chunks and students' writing proficiency? 3) What differences do students show in writing proficiency between the pre- and post-tests?

\section{Methods}

\subsection{Subjects}

This study took 68 art major freshmen as subjects and they were from two natural classes, but they have English course as one class. That is, they have the same English teacher and attend English course at the same time and in the same classroom. Among them, there were 26 males, taking up 38.2\%, and 42 females, accounting for $61.8 \%$. Their ages ranged from 17 to 20 . All subjects were not informed that they were participating in an experiment and they only believed they were taking regular English courses.

\subsection{Pre- and Post-Tests}

All the subjects were required to take a pre-test before the experiment and a post-test after the experiment. In both tests, the students were allowed to write a short essay with no less than 120 and no more than 150 words within 30 minutes. The pre-test was carried out to evaluate the students' writing proficiency before the experiment and its topic was "The Importance of Reading Ability". The post-test was undertaken after the experiment to examine whether students' writing proficiency have improved after the application of lexical approach through comparing the results of two tests and its topic was "The Importance of Writing Ability". Both topics of the tests were similar and were in close tie to students' daily life, and this can ensure the facility value of both writings was at the same level.

\subsection{Procedure}

The experiment lasted for a whole term, from March, 10th, 2019 to June, 30th, 2019 and the lexical approach was applied in this class. In the process of teaching, all kinds of teaching activities were designed to raise students' awareness of lexical chunks, such as identifying and classifying lexical chunks in the passage, translating with lexical chunks. Meanwhile, through productivity training methods, students in this class were offered as abundant opportunities as possible to produce and consolidate the lexical chunks learned in and out class. In a word, all the teaching designing and input- and output-activities are centered around the concept of lexical chunks. However, the present paper will not cover the activities about the learning and teaching of lexical chunks due to its limited space.

\subsection{Data Collection and Analysis}

The pre-test was conducted on March 6th, 2019 and the post-test was undertaken on June, 30th, 2019. After each test, the compositions were immediately collected and in each test there were 68 compositions, which shows there was no one absent from the tests.

After collecting the compositions, manual work was done by the author to pick out all the lexical chunks students in this class used respectively in the pre-test and the post-test. Then all the lexical chunks were classified into four types suggested by Nattinger and DeCarrico (1992) and the number of each type of lexical chunks was counted. The spelling errors and some errors such as ones in singular/plural use and in tense were neglected in the counting as long as the lexical chunks can be understood in the context.

After picking up and classifying the lexical chunks used in each composition, the author invited three experienced colleagues to rate all the compositions based on the writing criteria of CET-4. One of the colleagues has been working as a college English teacher for 18 years; the other two for 12 years. In addition, two of them have been rating compositions of CET-4 many times. The average score of these three teachers' was the final score for each composition. They rated all students' compositions of the two tests and the composition scores can reveal students' writing proficiency respectively in the pre-test and the post-test.

Then both composition scores and the number of lexical chunks were processed by SPSS 18 to find the answers to the research questions of this study.

\section{Results and Discussions}

\subsection{Use of Lexical Chunks}

The data of lexical chunks used by students in this class in the pre-test (see the raw data in Appendix A) and in the post-test (see the raw data in Appendix B) were processed by SPSS 18 to examine what difference(s) students show in the use of lexical chunks after the application of the lexical approach. 
Table 1. Descriptive Statistics of Lexical Chunks Used in the Pre-test

\begin{tabular}{lcllll}
\hline & $\mathrm{N}$ & Mean & Std. Deviation & Minimum & Maximum \\
\hline Polywords & 68 & 2.53 & 1.24 & 1.00 & 6.00 \\
Institutionalized expressions & 68 & 1.87 & 0.90 & 0.00 & 4.00 \\
Phrasal constraints & 68 & 2.81 & 0.87 & 1.00 & 4.00 \\
Sentence builders & 68 & 2.81 & 1.04 & 0.00 & 5.00
\end{tabular}

As shown in Table 1, the students in experiment do not use many lexical chunks in their writings of the pre-test. Among the four types of lexical chunks, phrasal constraints and sentence builders are used most frequently and they are equally used in writings on average, which is larger than that of the other two types of lexical chunks. Polywords take the second place and institutionalized expressions are used least and their mean value is only 1.87.

Table 2 lists the basic information about the number of lexical chunks used in the post-test by students in experiment. The table shows that the students in experiment use more lexical chunks in the post-test than they do in the pre-test, suggesting that they have made progress in the use of lexical chunks after the application of the lexical approach. From the table, it can be known that phrasal constraints are still used most frequently and their mean value reaches 3.82, which is higher than that in the pre-test. However, sentence builders take the second place and polywords are in the third place. Although institutionalized expressions are used least, their mean value increases from 1.87 in the pre-test to 2.38 in the post-test.

Table 2. Descriptive Statistics of Lexical Chunks Used in the Post-test

\begin{tabular}{llllll}
\hline & $\mathrm{N}$ & Mean & Std. Deviation & Minimum & Maximum \\
\hline Polywords & 68 & 3.35 & 1.16 & 1.00 & 7.00 \\
Institutionalized expressions & 68 & 2.38 & 0.83 & 1.00 & 5.00 \\
Phrasal constraints & 68 & 3.82 & 1.13 & 2.00 & 6.00 \\
Sentence builders & 68 & 3.75 & 0.98 & 2.00 & 7.00
\end{tabular}

The data in Tables 1 and 2 can show that the students of this class have made progress in the use of lexical chunks after the application of the lexical approach. In order to examine whether the progress students have made is significant or not, a paired samples $t$ test was conducted about the number of lexical chunks students used in both tests and the results can be seen in Table 3.

Table 3. Paired Samples T-test of Lexical Chunks Used in the Two Tests

\begin{tabular}{lcclll}
\hline \multicolumn{7}{c}{ Paired differences } \\
& Mean & Std. deviation & Std. error mean & $t$ & \multirow{2}{*}{ Sig. (2-tailed) } \\
\hline Polywords & 0.82 & 1.50 & 0.18 & 4.54 & .00 \\
Institutionalized expressions & 0.51 & 1.22 & 0.15 & 3.49 & .01 \\
Phrasal constraints & 1.01 & 1.49 & 0.18 & 5.61 & .00 \\
Sentence builders & 0.94 & 1.50 & 0.18 & 5.19 & .00
\end{tabular}

As shown in Table 3, all the mean differences are positive, suggesting that the students in experiment used more chunks of each type in the post-test than they did in the pre-test. It can be known from the table that there is significant difference in the use of all types of lexical chunks: polywords $(t=4.54, p<.05)$, institutionalized expressions $(t=3.49, p<.05)$, phrasal constraints $(t=5.61, p<.05)$, sentence builders $(t=5.19, p<.05)$, suggesting the students in experiment have made remarkable progress in the use of all types of lexical chunks.

However, students in experiment do not achieve the same progress in the use of sentence builders as in the use of phrasal constraints. In order to find the reasons for this, students' compositions are analyzed and it is found that students are not capable of employing the sentence builders correctly and flexibly and their writings lack the diversity in the use of sentence builders. Moreover, students may not have enough time to master sentence builders because the experiment lasts only for one semester. Finally, students are still greatly influenced by the 
traditional teaching methods and they do not devote much time to sentences. All the above reasons could account for the result that there is no same progress in the use of sentence builders and phrasal constraints.

\subsection{Correlations between Lexical Chunks and Writing Proficiency}

In order to find the correlations between students' use of lexical chunks and their writing proficiency, Pearson correlation coefficient test was conducted on composition scores of the post-test for students in experiment (see the raw data in Appendix C) and the number of lexical chunks used in the post-test by them.

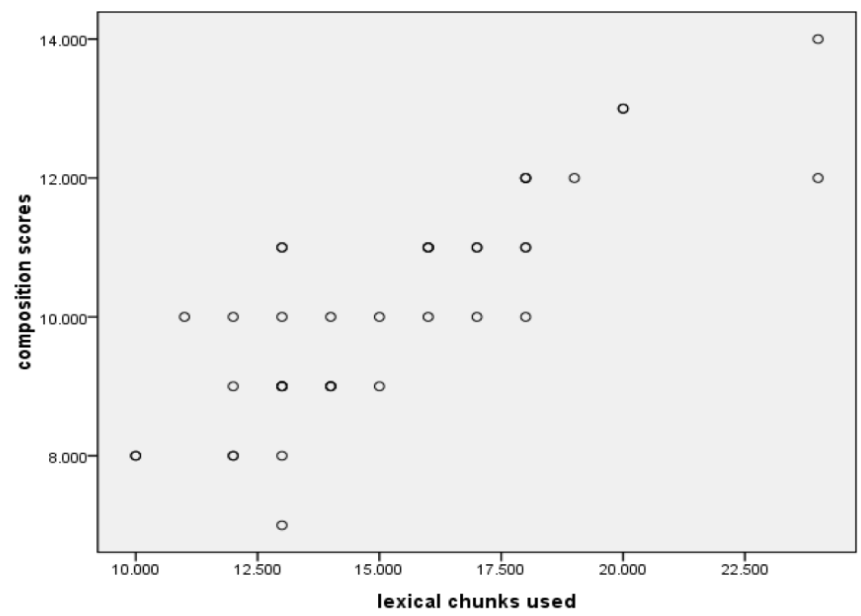

Figure 1. Scatter plots of chunks and composition scores in the post-test

Before the test of the Pearson correlation coefficient is conducted, it is necessary to find out whether there exist the linear relations between the number of lexical chunks and composition scores through scatter plots (see Figure 1).

As illustrated in Figure 1, there is the obvious rising tendency from the left bottom angle to the right up angle between the number of lexical chunks and composition scores, which indicates that there exists the possibility of linear and positive relations between the number of lexical chunks and composition scores. Therefore, it is feasible and reliable to examine whether there is the correlations between composition scores and the use of lexical chunks. Table 4 lists Pearson correlation between the number of lexical chunks and composition scores.

Table 4. Correlations between the Use of Lexical Chunks and Composition Scores of the Post-test

\begin{tabular}{lllllll}
\hline & & Polywords & $\begin{array}{l}\text { Institutionalized } \\
\text { expressions }\end{array}$ & $\begin{array}{l}\text { Phrasal } \\
\text { constraints }\end{array}$ & $\begin{array}{l}\text { Sentence } \\
\text { builders }\end{array}$ & $\begin{array}{l}\text { Total } \\
\text { number }\end{array}$ \\
\hline $\begin{array}{l}\text { Composition } \\
\text { scores }\end{array}$ & Pearson correlation & 0.44 & 0.16 & 0.55 & 0.26 & 0.61 \\
& Sig. (2-tailed) & 0.00 & 0.18 & 0.00 & 0.03 & 0.00 \\
\hline
\end{tabular}

From Table 4, it can be known that the composition scores are in positive correlation $(r=0.61$ at $p<.05)$ with the total number of lexical chunks used in writings. This means that the students' writing scores are positively co-varying in accordance with the number of lexical chunks used in their writings. In other words, the more lexical chunks students use in their writings, the higher scores they tend to get.

Table 4 also shows the correlations between composition scores and the number of lexical chunks in each type. In terms of the correlation between composition scores and the use of lexical chunks in each type, composition scores are in significant correlation $(r=0.55$ at $p<0.05)$ with phrasal constraints. For the same category of correlation, composition scores are also in significant correlation $(r=0.44$ at $p<0.05)$ with polywords. and in low correlation $(r=0.26$ at $p<0.05)$ with sentence builders. However, there is no significant correlation between students' composition scores and their use of institutionalized expressions $(r=0.16$ at $p>.05)$. The reason behind this probably lies in that institutionalized expressions mainly function in spoken discourse rather than in written discourse. The data also shows that the use of phrasal constraints contributes most to students' writing scores and it is followed by polywords and sentence builders. This result is in accordance with the findings in Section 3.1 that students make significant progress in the use of lexical chunks in the post-test. 


\subsection{Comparisons of Compositions Scores}

The post-test composition scores (see the raw data in Appendix C) were analyzed in comparison with those in the pre-test (see the raw data in Appendix D) by using descriptive statistics and t-tests to find out whether students' writing proficiency still stays at the same level after they have received different treatments. The results are shown in Table 5.

Table 5. Descriptive Statistics of Composition Scores in Two Tests

\begin{tabular}{llllll}
\hline & $N$ & Mean & Std. deviation & Minimum & Maximum \\
\hline Post-test & 68 & 7.37 & 1.48 & 5.00 & 11.00 \\
Pre-test & 68 & 5.72 & 1.33 & 3.00 & 9.00
\end{tabular}

As shown in Table 5, the writing's mean score in the pre-test is 5.72 and the standard deviation is 1.33 ; while the mean score of the writing for post-test is 7.37, which is higher than that in the pre-test and the standard deviation is 1.48 . The lowest score is 5.00 and the highest score reaches 11.00 in post-test; while in pre-test, it is 3.00 and 9.00 respectively. This result indicates that the students in post-test have higher level in writing proficiency than that in pre-test after the experiment. This can be further proved by the data in Table 6 .

Table 6. Paired Samples T-test of Composition Scores

\begin{tabular}{llllll}
\hline \multicolumn{2}{l}{ Paired differences } & & & \\
\hline & Mean & Std. deviation & Std. error & $t$ & Sig. (2-tailed) \\
\hline Posttest -Pretest & 1.65 & 1.26 & 0.15 & 10.82 & 0.00
\end{tabular}

Table 6 shows that the students' average score has increased by 1.65 points in the post-test in comparison with that of the pre-test. This implies that students have achieved advancement in writing proficiency. Moreover, it can be found from the table that there is significant difference $(t=10.82, p<.05)$ between the pre-test scores and the post-test scores for students, suggesting that students in experiment have made obvious progress in their writing proficiency under the instruction of the lexical approach for one semester.

The analysis and results in this part can provide answer to the third research question: The students have shown differences in writing proficiency after applying the lexical approach in this class in comparison with their writing proficiency before the experiment. In view of the correlations between the use of lexical chunks and the composition scores (this has been analyzed in section 3.2), the progress made by students in this experiment can be attributed to the lexical approach applied in their reading and writing course.

\section{Conclusion}

\subsection{Major Findings of the Study}

From the analysis and discussions of relevant data, the major findings can be summarized as follows:

Firstly, the students use more lexical chunks in the post-test than in the pre-test and they make significant progress in the use of all types of lexical chunks. This implies that lexical approach can enhance students' lexical ability.

Secondly, the use of lexical chunks in writings is in positive correlations with students' writing proficiency. The statistical results of correlation test shows that the use of lexical chunks could help students get higher scores in writings. The more chunks students use, the higher scores they can get.

Thirdly, students in this class have made progress in writing proficiency after one semester's learning and they get higher composition scores in the post-test on average than that in the pre-test. This can be mainly attributed to the lexical approach used in this class.

All the findings can show that the lexical approach has positive effect on art majors' writing proficiency. So it is quite feasible and effective to apply the lexical approach to English teaching, especially in English writing teaching.

\subsection{Limitations of the Study}

Although the author has tried his utmost to examine the effects that the lexical approach has on writing proficiency through applying it in college English reading and writing course, the present study is far from perfect in a real academic sense due to some subjective factors and there are some limitations in this study that need to be pointed out. 
First of all, this teaching experiment lasts only for nearly four months, which are not long enough to well verify the effect of the lexical approach. Because students need longer time to adapt to this unfamiliar teaching method, and this might affect the effect of English learning.

The second limitation is that there are limited participants. Only 68 art major freshmen from one English class in one University are selected as subjects for the present study. The number of the subjects is relatively small and they can't represent the overall level of all the art major students in China. This drawback might reduce the universality and persuasion of the experiment.

Finally, this study only explores the application of lexical approach and analyzes the data of composition scores but without adopting any questionnaire. The future study can adopt a corresponding questionnaire and then more reliable and valid information could be found.

\section{References}

Chen, W. (2008). Raise students' consciousness of lexical chunks and improve students' writing. Foreign Language World, 3, 48-53.

Ding, Y., \& Qi, Y. (2005). Use of formulaic as a predictor of L2 oral and written performance. Journal of PLA University of Foreign Languages, 3, 49-53.

$\mathrm{Du}, \mathrm{Z}$. (2016). A corpus-based study on the structural and functional features of lexical chunks in Chinese academic English. Technology Enhanced Foreign Language Education, 10, 9-13.

Ellis, R. (1999). The study of second language acquisition. Shanghai, China: Foreign Language Teaching and Research Press.

Gai, S. (2010). An empirical study of chunking acquisition in the zone of proximal development: an experiment of scaffolding chunking approach. Foreign Languages and Their Teaching, 5, 68-72.

Gao, X. (2017). A comparable-corpus-based study on native English and Chinese academic writers' use of English lexical bundles. Foreign Languages and Their Teaching, 3, 42-50.

Han, X. (2011). The influence of lexical modifications on college students' English acquisition. Foreign Language Research, 3, 96-99.

$\mathrm{Hu}$, Y. (2015). A corpus-based study of structural features of lexical bundles in English major's oral performance. Foreign Languages Research, 5, 26-30.

Lewis, M. (1993). The lexical approach. Hove, England: Language Teaching Publications.

Lewis, M. (2000). Teaching collocations. Hove, England: Language Teaching Publications.

Ma, G. (2009). Lexical bundles in L2 timed writing of English majors. Foreign Language Teaching and Research, 1, 54-60.

Nattinger, J., \& DeCarrico, J. (1992). Lexical phrases and language teaching. Oxford, England: Oxford University Press.

Perera, N. S. (2001). The role of prefabricated language in young children's second language acquisition. Bilingual Research Journal, 25, 327-356. https://doi.org/10.1080/15235882.2001.10162797

Qi, Y. (2005). Prefabricated chunk and college English writing. Shandong Foreign Language Teaching, 5, 64-66.

Qi, Y., \& Ding, Y. (2011). A contrastive analysis of chunk features in oral English for Chinese and American college students. Foreign Language World, 3, 52-59.

Richards, J. C., \& Rodgers, T. S. (2008). Approaches and methods in language teaching. Beijing, China: Foreign Language Teaching and Research Press.

$\mathrm{Xu}, \mathrm{X}$. (2010). The lexical bundle use in L2 writings by non-English major postgraduates. Foreign Language World, 5, 42-47.

Yang, Y. (2015). The use of lexical bundles in Chinese English majors' and American college students' writings. Foreign Language World, 3, 51-58.

Zhang, Y. (2008). An empirical study on the correlation between Chinese L2 leaners' ability to identify chunks and their L2 proficiency. Foreign Language World, 3, $42-47$. 


\section{Appendix A}

The Number of Lexical Chunks Used in the Pre-test

\begin{tabular}{|c|c|c|c|c|}
\hline Number & Polywords & $\begin{array}{l}\text { Institutionalized } \\
\text { expressions }\end{array}$ & $\begin{array}{l}\text { Phrasal } \\
\text { constraints }\end{array}$ & Sentence builders \\
\hline 1 & 2 & 1 & 2 & 3 \\
\hline 2 & 5 & 1 & 4 & 4 \\
\hline 3 & 2 & 0 & 3 & 4 \\
\hline 4 & 3 & 3 & 3 & 4 \\
\hline 5 & 3 & 0 & 2 & 2 \\
\hline 6 & 3 & 2 & 2 & 1 \\
\hline 7 & 1 & 1 & 3 & 0 \\
\hline 8 & 2 & 1 & 2 & 3 \\
\hline 9 & 3 & 2 & 3 & 1 \\
\hline 10 & 1 & 2 & 3 & 2 \\
\hline 11 & 2 & 2 & 3 & 3 \\
\hline 12 & 4 & 2 & 4 & 3 \\
\hline 13 & 1 & 1 & 3 & 4 \\
\hline 14 & 3 & 1 & 3 & 2 \\
\hline 15 & 2 & 3 & 1 & 3 \\
\hline 16 & 5 & 2 & 2 & 2 \\
\hline 17 & 1 & 2 & 1 & 0 \\
\hline 18 & 4 & 3 & 3 & 1 \\
\hline 19 & 2 & 1 & 3 & 3 \\
\hline 20 & 3 & 2 & 2 & 2 \\
\hline 21 & 3 & 2 & 2 & 3 \\
\hline 22 & 1 & 2 & 4 & 3 \\
\hline 23 & 2 & 1 & 3 & 3 \\
\hline 24 & 4 & 3 & 3 & 3 \\
\hline 25 & 3 & 1 & 2 & 3 \\
\hline 26 & 1 & 2 & 3 & 4 \\
\hline 27 & 4 & 3 & 1 & 3 \\
\hline 28 & 3 & 0 & 3 & 2 \\
\hline 29 & 5 & 3 & 1 & 3 \\
\hline 30 & 2 & 3 & 4 & 4 \\
\hline 31 & 1 & 1 & 2 & 2 \\
\hline 32 & 2 & 2 & 3 & 2 \\
\hline 33 & 3 & 2 & 4 & 3 \\
\hline 34 & 3 & 4 & 4 & 3 \\
\hline 35 & 4 & 3 & 3 & 4 \\
\hline 36 & 2 & 2 & 3 & 2 \\
\hline 37 & 1 & 2 & 3 & 4 \\
\hline 38 & 2 & 1 & 2 & 2 \\
\hline
\end{tabular}




\begin{tabular}{|c|c|c|c|c|}
\hline 39 & 1 & 3 & 3 & 4 \\
\hline 40 & 2 & 2 & 4 & 3 \\
\hline 41 & 1 & 3 & 4 & 3 \\
\hline 42 & 3 & 1 & 3 & 2 \\
\hline 43 & 2 & 3 & 2 & 3 \\
\hline 44 & 5 & 2 & 3 & 2 \\
\hline 45 & 1 & 2 & 2 & 0 \\
\hline 46 & 4 & 3 & 4 & 3 \\
\hline 47 & 2 & 1 & 3 & 3 \\
\hline 48 & 3 & 2 & 2 & 2 \\
\hline 49 & 3 & 2 & 2 & 3 \\
\hline 50 & 1 & 2 & 4 & 3 \\
\hline 51 & 2 & 1 & 3 & 2 \\
\hline 52 & 4 & 3 & 4 & 3 \\
\hline 53 & 3 & 1 & 3 & 4 \\
\hline 54 & 1 & 2 & 3 & 5 \\
\hline 55 & 4 & 3 & 1 & 4 \\
\hline 56 & 3 & 0 & 3 & 3 \\
\hline 57 & 6 & 1 & 1 & 3 \\
\hline 58 & 2 & 1 & 4 & 4 \\
\hline 59 & 1 & 1 & 3 & 2 \\
\hline 60 & 2 & 2 & 3 & 3 \\
\hline 61 & 3 & 2 & 4 & 2 \\
\hline 62 & 3 & 2 & 3 & 3 \\
\hline 63 & 4 & 3 & 3 & 4 \\
\hline 64 & 2 & 2 & 4 & 3 \\
\hline 65 & 1 & 2 & 3 & 4 \\
\hline 66 & 2 & 1 & 2 & 3 \\
\hline 67 & 1 & 3 & 3 & 4 \\
\hline 68 & 2 & 2 & 3 & 4 \\
\hline
\end{tabular}




\section{Appendix B}

The Number of Lexical Chunks Used in the Post-test

\begin{tabular}{|c|c|c|c|c|}
\hline Number & Polywords & $\begin{array}{l}\text { Institutionalized } \\
\text { expressions }\end{array}$ & $\begin{array}{l}\text { Phrasal } \\
\text { constraints }\end{array}$ & Sentence builders \\
\hline 1 & 5 & 3 & 4 & 4 \\
\hline 2 & 7 & 2 & 4 & 4 \\
\hline 3 & 4 & 2 & 4 & 5 \\
\hline 4 & 4 & 3 & 4 & 3 \\
\hline 5 & 3 & 1 & 5 & 4 \\
\hline 6 & 4 & 2 & 3 & 6 \\
\hline 7 & 2 & 4 & 4 & 4 \\
\hline 8 & 4 & 1 & 5 & 3 \\
\hline 9 & 3 & 3 & 6 & 5 \\
\hline 10 & 3 & 3 & 3 & 4 \\
\hline 11 & 3 & 1 & 3 & 3 \\
\hline 12 & 3 & 2 & 4 & 3 \\
\hline 13 & 3 & 2 & 4 & 4 \\
\hline 14 & 3 & 5 & 5 & 7 \\
\hline 15 & 4 & 3 & 4 & 6 \\
\hline 16 & 5 & 3 & 6 & 3 \\
\hline 17 & 1 & 2 & 3 & 4 \\
\hline 18 & 1 & 2 & 2 & 3 \\
\hline 19 & 3 & 3 & 3 & 4 \\
\hline 20 & 3 & 2 & 2 & 5 \\
\hline 21 & 1 & 3 & 3 & 4 \\
\hline 22 & 5 & 1 & 4 & 5 \\
\hline 23 & 4 & 2 & 3 & 4 \\
\hline 24 & 4 & 3 & 5 & 4 \\
\hline 25 & 3 & 1 & 4 & 3 \\
\hline 26 & 3 & 2 & 5 & 3 \\
\hline 27 & 4 & 1 & 3 & 3 \\
\hline 28 & 4 & 3 & 2 & 3 \\
\hline 29 & 5 & 2 & 5 & 4 \\
\hline 30 & 4 & 2 & 3 & 3 \\
\hline 31 & 3 & 3 & 4 & 3 \\
\hline 32 & 5 & 2 & 5 & 3 \\
\hline 33 & 2 & 3 & 3 & 3 \\
\hline 34 & 4 & 2 & 5 & 4 \\
\hline 35 & 5 & 4 & 6 & 3 \\
\hline 36 & 3 & 4 & 5 & 2 \\
\hline 37 & 6 & 2 & 3 & 3 \\
\hline 38 & 2 & 3 & 5 & 2 \\
\hline
\end{tabular}




\begin{tabular}{|c|c|c|c|c|}
\hline 39 & 3 & 1 & 3 & 4 \\
\hline 40 & 2 & 2 & 4 & 4 \\
\hline 41 & 2 & 2 & 4 & 4 \\
\hline 42 & 4 & 2 & 6 & 3 \\
\hline 43 & 2 & 3 & 2 & 6 \\
\hline 44 & 3 & 3 & 2 & 3 \\
\hline 45 & 3 & 2 & 3 & 4 \\
\hline 46 & 3 & 2 & 4 & 3 \\
\hline 47 & 4 & 3 & 3 & 4 \\
\hline 48 & 3 & 2 & 3 & 5 \\
\hline 49 & 4 & 3 & 5 & 4 \\
\hline 50 & 3 & 2 & 2 & 5 \\
\hline 51 & 3 & 2 & 4 & 3 \\
\hline 52 & 3 & 3 & 3 & 3 \\
\hline 53 & 3 & 1 & 4 & 3 \\
\hline 54 & 4 & 2 & 4 & 4 \\
\hline 55 & 5 & 3 & 6 & 5 \\
\hline 56 & 3 & 3 & 4 & 3 \\
\hline 57 & 3 & 2 & 4 & 4 \\
\hline 58 & 2 & 2 & 4 & 3 \\
\hline 59 & 4 & 3 & 5 & 4 \\
\hline 60 & 2 & 2 & 2 & 3 \\
\hline 61 & 3 & 3 & 4 & 4 \\
\hline 62 & 3 & 2 & 3 & 3 \\
\hline 63 & 4 & 3 & 4 & 4 \\
\hline 64 & 2 & 1 & 2 & 2 \\
\hline 65 & 2 & 2 & 5 & 3 \\
\hline 66 & 2 & 3 & 2 & 3 \\
\hline 67 & 4 & 3 & 3 & 4 \\
\hline 68 & 5 & 3 & 5 & 5 \\
\hline
\end{tabular}




\section{Appendix C}

\section{Composition Scores of Post-test}

\begin{tabular}{|c|c|c|c|}
\hline Number & Score & Number & Score \\
\hline 1 & 6 & 35 & 10 \\
\hline 2 & 9 & 36 & 6 \\
\hline 3 & 8 & 37 & 5 \\
\hline 4 & 7 & 38 & 5 \\
\hline 5 & 7 & 39 & 6 \\
\hline 6 & 6 & 40 & 8 \\
\hline 7 & 7 & 41 & 7 \\
\hline 8 & 7 & 42 & 9 \\
\hline 9 & 9 & 43 & 5 \\
\hline 10 & 5 & 44 & 6 \\
\hline 11 & 6 & 45 & 8 \\
\hline 12 & 8 & 46 & 8 \\
\hline 13 & 8 & 47 & 9 \\
\hline 14 & 8 & 48 & 8 \\
\hline 15 & 8 & 49 & 10 \\
\hline 16 & 11 & 50 & 7 \\
\hline 17 & 7 & 51 & 6 \\
\hline 18 & 6 & 52 & 6 \\
\hline 19 & 6 & 53 & 6 \\
\hline 20 & 6 & 54 & 8 \\
\hline 21 & 8 & 55 & 10 \\
\hline 22 & 10 & 56 & 8 \\
\hline 23 & 8 & 57 & 7 \\
\hline 24 & 7 & 58 & 7 \\
\hline 25 & 7 & 59 & 9 \\
\hline 26 & 9 & 60 & 6 \\
\hline 27 & 6 & 61 & 8 \\
\hline 28 & 7 & 62 & 7 \\
\hline 29 & 7 & 63 & 9 \\
\hline 30 & 9 & 64 & 5 \\
\hline 31 & 5 & 65 & 7 \\
\hline 32 & 7 & 66 & 6 \\
\hline 33 & 6 & 67 & 9 \\
\hline 34 & 9 & 68 & 10 \\
\hline
\end{tabular}




\section{Appendix D}

\section{Composition Scores of Pre-test}

\begin{tabular}{|c|c|c|c|}
\hline Number & Score & Number & Score \\
\hline 1 & 5 & 35 & 8 \\
\hline 2 & 9 & 36 & 5 \\
\hline 3 & 5 & 37 & 5 \\
\hline 4 & 6 & 38 & 4 \\
\hline 5 & 4 & 39 & 6 \\
\hline 6 & 4 & 40 & 7 \\
\hline 7 & 5 & 41 & 5 \\
\hline 8 & 5 & 42 & 6 \\
\hline 9 & 6 & 43 & 4 \\
\hline 10 & 4 & 44 & 6 \\
\hline 11 & 6 & 45 & 7 \\
\hline 12 & 7 & 46 & 5 \\
\hline 13 & 5 & 47 & 6 \\
\hline 14 & 6 & 48 & 5 \\
\hline 15 & 5 & 49 & 6 \\
\hline 16 & 6 & 50 & 3 \\
\hline 17 & 3 & 51 & 6 \\
\hline 18 & 6 & 52 & 4 \\
\hline 19 & 4 & 53 & 5 \\
\hline 20 & 5 & 54 & 5 \\
\hline 21 & 5 & 55 & 7 \\
\hline 22 & 7 & 56 & 5 \\
\hline 23 & 5 & 57 & 8 \\
\hline 24 & 8 & 58 & 6 \\
\hline 25 & 6 & 59 & 7 \\
\hline 26 & 7 & 60 & 6 \\
\hline 27 & 6 & 61 & 6 \\
\hline 28 & 6 & 62 & 6 \\
\hline 29 & 6 & 63 & 8 \\
\hline 30 & 8 & 64 & 4 \\
\hline 31 & 4 & 65 & 5 \\
\hline 32 & 5 & 66 & 5 \\
\hline 33 & 5 & 67 & 8 \\
\hline 34 & 8 & 68 & 8 \\
\hline
\end{tabular}

\section{Copyrights}

Copyright for this article is retained by the author(s), with first publication rights granted to the journal.

This is an open-access article distributed under the terms and conditions of the Creative Commons Attribution license (http://creativecommons.org/licenses/by/4.0/). 